\title{
Uterine Rupture among Women who Gave Birth at Nekemte Referral Hospital: Case Control Study
}

\section{Temesgen Tilahun Bekabil}

Wollega University, Nekemte, Oromia, Ethiopia

*Corresponding author: Temesgen Tilahun Bekabil, Wollega University, Nekemte, Oromia, Ethiopia, Tel: +251912057186; E-mail: ttamuko@yahoo.com

Received date: January 05, 2018; Accepted date: February 07, 2018; Published date: February 14, 2018

Copyright: ( 2018 Bekabil TT. This is an open-access article distributed under the terms of the Creative Commons Attribution License, which permits unrestricted use, distribution and reproduction in any medium, provided the original author and source are credited.

\begin{abstract}
Background: Uterine rupture is an obstetrics complication which is still both clinical dilemma and broader public health problem in developing countries.

Objectives: This study is aimed to establish the magnitude of uterine rupture, predisposing factors, maternal and fetal outcomes, and surgical options of management of uterine rupture at Nekemte referral hospital which is located in western Ethiopia.

Methods: Case control study was conducted on 54 mothers with uterine rupture and 108 mothers for whom cesarean section was done for mechanical reasons or previous scar who were managed in the Obstetrics and Gynecologic ward of the hospital from July 2015 to July 2016. Data were collected from two groups by accessing medical records. Statistical Package for Social Sciences windows version 20 was used for data analysis. The association between uterine rupture and different variables were assessed by using odds ratio (OR) along with $95 \% \mathrm{Cl}$.

Results: A total of 3,808 deliveries were conducted during the study period. There were 3206 vaginal deliveries, 548 cesarean deliveries and 54 uterine rupture cases. This makes 1 uterine rupture to happen in 70.5 deliveries. Majority, $87 \%$, of uterine rupture occurred in unscarred uterus. The predisposing factors for uterine rupture were parity $\geq 5(\mathrm{OR}=4.37,95 \% \mathrm{Cl}: 1.05,18.23)$, lack of antenatal care $(\mathrm{OR}=7,95 \% \mathrm{Cl}: 1.81,27.02)$, lack of formal education $(\mathrm{OR}=2.38,95 \% \mathrm{Cl}: 1.08,5.26)$, household income less than 100 United States' Dollar (OR=14.08, 95\% $\mathrm{Cl}: 3.25,62.5)$, previous home delivery (OR=9.10, 95\% Cl: $3.92,21.11)$, and intrapartal follow up at health center or private clinics $(\mathrm{OR}=24.14,95 \% \mathrm{Cl}: 5.60,104.15)$. Uterine rupture caries more maternal $(1.85 \%$ vs. $0 \%)$ and neonatal mortalities ( $96.3 \%$ vs. $3.7 \%$ ) when compared to mothers delivered by cesarean section.
\end{abstract}

Conclusion: Magnitude of uterine rupture was high in the study area. It carries more maternal and perinatal complications. There were numerous modifiable predisposing factors.

Keywords: Uterine rupture; Obstetric care; Hysterectomy

\section{Abbreviations}

ANC: Antenatal Care; NICU: Neonatal Intensive Care Unit; USD: United States' Dollar

\section{Introduction}

Worldwide, every year, between 340,000 and half a million women die due to complications of pregnancy and child birth, the majority of these occurring in low income countries. Sub- Sahara Africa bears over $90 \%$ of the burden. Among the major causes, uterine rupture remains as one of obstetrics dilemmas that needs better attention and is a reflector of poor obstetric care in a given setting [1-3]. Hospital based studies in Ethiopia showed uterine rupture as one of major obstetric challenges causing various maternal and perinatal complications $[4,5]$.

Uterine rupture is tearing of the uterine wall partially or completely during pregnancy or delivery. Its occurrence varies in different parts of the world depending on different factors. For instance, it ranges from one in few deliveries in rural Africa, where poverty is deep rooted, to one in many thousand deliveries in industrialized countries [1-4,6].

Ruptured uterus is associated with numerous factors and causes [2,5-9], most of which can be tackled by having improved healthcare delivery, access to quality antenatal care and family planning $[1,4]$. Studies in Ethiopia identified obstructed labor as leading cause of uterine rupture $[4,5,9]$.

It is one of the major catastrophic obstetric event that caries significant maternal and perinatal mortality and morbidity. Despite global effort to improve obstetric care, uterine rupture is still causing maternal deaths in developing countries particularly in sub-Saharan Africa where there is inadequate medical care or limited access due to various reasons $[1,8]$. Prompt interventions are keys to good foetal \& maternal outcome $[6,7]$. 
Page 2 of 6

\section{Methods}

\section{Study design and setting}

Case control study was conducted on 54 mothers with uterine rupture as cases and 108 mothers for whom cesarean section was done for mechanical reasons or previous scar as control group who were managed in the Obstetrics and Gynecologic ward of the hospital from July 2015 to July 2016. The study was conducted at Nekemte referral Hospital, found in Nekemte town, geographically located $331 \mathrm{kms}$ west of Addis Ababa. It was established in 1932 E.C with Swedish funds and contributions from Emperor Haile Selassie. The Hospital has 178 beds and it has different units. Gynecology and obstetrics unit is run by two obstetricians and gynecologists, two emergency surgeons, one general practitioner and 15 midwives. The hospital has also NICU run by two pediatricians.

\section{Study population}

All women who gave birth in Nekemte referral Hospital from July 1, 2015-July 30, 2016 were study population. Cases were all intrapartum uterine ruptures after 28 weeks of gestational age. The cases were retrospectively collected from the labor and maternity wards, operating theatre registers and the files of patients at the hospital medical records office.

Controls were mothers who delivered by caesarean section for mechanical reasons or previous scar with additional factor(s) like declined trial of labor, contracted pelvis, or fetal reasons.

\section{Sample size and sampling techniques}

All women with uterine rupture, 54 uterine rupture cases, were included in the study. For each uterine rupture, two mothers who gave birth by caesarean section for mechanical reasons or previous scar with additional factor(s) happening just next to the uterine rupture were taken as control group. All deliveries and rupture cases admitted to labor or maternity ward and terminated prior to gestational age of 28 weeks were excluded from this study.

\section{Data collection procedures}

Medical records (labor and maternity wards and operation theatre) of all patients were accessed and data were collected by using structured questionnaire which was developed after reviewing different related literatures. Five midwives and two medical interns were recruited and trained on how to collect data from patient files, charts and/or operation theatre registry and fill the data. They were also oriented on how to select the controls. All completed questionnaires were checked for completeness by the principal investigator.

\section{Data management and analysis}

The collected data were entered to, cleaned and analysed by using SPSS for windows version 20.0. Descriptive statistics such as proportions means and standard deviations were determined to describe the study participants by cross-tabulating according to their exposure status. Odds ratio (OR) along with their 95\% confidence intervals (CI) were determined to measure the existence of significant associations between uterine rupture and each predisposing factor or complications. Ratios with $95 \%$ CI were used to show the magnitude and significance of the associations.

\section{Ethical Considerations}

The ethical clearance was taken from the College of medical and health sciences of Wollega university ethical research committee. Permission to clerk the study participants and access to obstetric records and logbooks was obtained from Nekemte referral hospital and these were anonymously entered into the database. Written informed consent was obtained from every study subject before the interview by explaining the objective of the research. All the information collected from the study subjects were handled confidentially through omitting their personal identification, conducting the interview in private place and the data will be used for the research purpose only.

\section{Results}

\section{Magnitude of uterine rupture and sociodemographic characteristics of the study participants}

A total of 3,808 deliveries were conducted from July 2015 to July 2016. There were 3206 vaginal deliveries, 548 cesarean deliveries and 54 uterine rupture cases. This makes 1 uterine rupture to happen in 70.5 deliveries.

Most of the study participants were from Oromo ethnic group $(81.5 \%)$, protestant in religion $(44.4 \%)$, house wife $(52.5 \%)$, and with no formal education (70.4\%). Majority of the deliveries (89.5\%), both in cases and control groups, were from mothers aged 20 to 34 years as depicted in Table 1.

\begin{tabular}{|l|l|l|l|l|}
\hline \multicolumn{2}{|c|}{ Sociodemographic variables } & \multicolumn{3}{c|}{ Study groups } \\
\cline { 2 - 5 } & \multicolumn{1}{|c|}{$\begin{array}{c}\text { Cases (uterine } \\
\text { rupture) }(\mathbf{n = 5 4 )} \mathbf{n}(\%)\end{array}$} & $\begin{array}{c}\text { Control group (cesarean } \\
\text { deliveries) (n=108) } \mathbf{n}(\%)\end{array}$ & Total (n=162) $\mathbf{n}(\%)$ \\
\hline \multirow{3}{*}{ Age in years } & $\leq 19$ & $0(0)$ & $3(2.8)$ & $3(1.9)$ \\
\cline { 2 - 6 } & 20 to 34 & $47(87)$ & $98(90.7)$ & $145(89.5)$ \\
\cline { 2 - 6 } & $\geq 35$ & $7(13)$ & $7(6.5)$ & $14(8.6)$ \\
\hline \multirow{2}{*}{ Ethnicity } & Oromo & $48(88.9)$ & $84(77.8)$ & $132(81.5)$ \\
\cline { 2 - 6 } & Amhara & $6(11.1)$ & $24(22.2)$ & $30(18.5)$ \\
\hline Religion & Orthodox & $17(31.5)$ & $51(47.2)$ & $68(41.9)$ \\
\hline
\end{tabular}


Citation: Bekabil TT (2018) Uterine Rupture among Women who Gave Birth at Nekemte Referral Hospital: Case Control Study. Biol Med (Aligarh) 10: 430. doi:10.4172/0974-8369.1000430

Page 3 of 6

\begin{tabular}{|c|c|c|c|c|}
\hline & Protestant & $27(50)$ & $45(41.7)$ & $72(44.4)$ \\
\hline & Muslim & $10(18.5)$ & $12(11.1)$ & $22(13.6)$ \\
\hline \multirow{4}{*}{ Occupation } & Housewife & $12(22.2)$ & $73(67.6)$ & $85(52.5)$ \\
\hline & Farmer & $36(66.7)$ & $1(0.9)$ & $37(22.8)$ \\
\hline & Merchant & $5(9.3)$ & $11(10.2)$ & $16(9.9)$ \\
\hline & Governmental employee & $1(1.9)$ & $23(21.3)$ & $24(14.8)$ \\
\hline \multirow{2}{*}{ Educational status } & No formal education & $44(81.5)$ & $70(64.8)$ & $114(70.4)$ \\
\hline & Formal education & $10(8.5)$ & $38(35.2)$ & $48(29.6)$ \\
\hline \multirow{2}{*}{ Parity } & 1 to 4 & $42(77.8)$ & $93(86.1)$ & $135(83.3)$ \\
\hline & $\geq 5$ & $12(22.2)$ & $15(13.9)$ & $27(16.7)$ \\
\hline
\end{tabular}

Table 1: Sociodemographic characteristics of the study participants at Nekemte Referral Hospital from July 2015 to July 2016.

\section{Maternal characteristics of study participants by means of obstetrics factors}

The mean maternal age in years for cases of uterine rupture and those who gave birth by cesarean section were $27.4 \pm 5.1$ and $25.9 \pm 4.6$ at $\mathrm{p}$-value $=0.670$ whereas the mean number of parity were $3.3 \pm 1.6$ and $2.1 \pm 1.0$ at $\mathrm{p}$-value $=0.00$ for mothers with uterine rupture and those who gave birth by cesarean section respectively. The mean duration of pushing down pain in hours for cases of uterine rupture and those who gave birth by cesarean section were $12.6 \pm 5.4$ and $9.5 \pm$ 5.6 at $\mathrm{p}$-value $=0.001$ respectively as shown in Table 2 .

\begin{tabular}{|l|l|l|l|}
\hline \multirow{2}{*}{ Sociodemographic variables } & \multicolumn{2}{|c|}{ Study groups } & Control group (cesarean deliveries) $(\mathbf{n = 1 0 8 )} \mathbf{n}(\%)$ \\
\cline { 2 - 4 } & Cases (uterine rupture) $\mathbf{( n = 5 4 )} \mathbf{n}(\%)$ & \multicolumn{1}{|c|}{0} \\
\hline Mean age of mother in years & $27.4 \pm 5.1$ & $25.9 \pm 4.6$ & 0.67 \\
\hline $\begin{array}{l}\text { Mean monthly household income in } \\
\text { USD }\end{array}$ & $\$ 57.8 \pm 48.9$ & $\$ 84.7 \pm 48.4$ & 0.001 \\
\hline Mean parity in number & $3.3 \pm 1.6$ & $2.1 \pm 1.0$ & 0 \\
\hline $\begin{array}{l}\text { Mean duration of pushing down pain } \\
\text { in hours }\end{array}$ & $12.6 \pm 5.4$ & $9.5 \pm 5.6$ & 0.001 \\
\hline $\begin{array}{l}\text { Mean duration of rupture of } \\
\text { membrane in hours }\end{array}$ & $3.5 \pm 3.8$ & $3.7 \pm 3.7$ & 0.813 \\
\hline Note: USD: United States' Dollar & & & \\
\hline
\end{tabular}

Table 2: Maternal characteristics of study participants by means of age, income, parity, duration of pushing down pain and rupture of membrane at Nekemte Referral Hospital from July 2015 to July 2016.

\section{Associated risk factors for uterine rupture at Nekemte Referral Hospital}

The predisposing factors for uterine rupture were parity $\geq 5$ $(\mathrm{OR}=4.37,95 \% \mathrm{CI}: 1.05,18.23)$, lack of $\mathrm{ANC}(\mathrm{OR}=7,95 \% \mathrm{CI}: 1.81$, 27.02), lack of formal education ( $\mathrm{OR}=2.38,95 \% \mathrm{CI}: 1.08,5.26)$, household income less than $100 \mathrm{USD}(\mathrm{OR}=14.08,95 \%$ CI: 3.25, 62.5), previous home delivery $(\mathrm{OR}=9.10,95 \% \mathrm{CI}: 3.92,21.11)$, intrapartal follow up at health center or private clinics(OR=24.14, 95\% CI: 5.60, 104.15) but factors like advanced maternal age, use of uterotonic agents and instrumental deliveries or previous cesarean section were not found to increase the risk of uterine rupture.

Eighty seven percent $(87 \%)$ of uterine rupture occurred in unscarred uterus and history of previous uterine scar was only reported in $13 \%$. Intervention by oxytocin/instrumental delivery was documented in $7.2 \%$ of mothers who had uterine rupture. Oxytocin was used in $5.6 \%$ of mothers who delivered by cesarean section when compared to $1.9 \%$ mothers with uterine rupture whereas instrumental deliveries were tried in mothers with uterine rupture and cesarean delivery cases $(5.6 \%$ vs. $1.9 \%)$ respectively.

\section{Levels of delay and characteristics of uterine rupture at Nekemte Referral Hospital}

In this study, the magnitude of complete uterine rupture is the same as incomplete one. Hysterectomy was done for $61.1 \%$ of the cases while the uterus was repaired for $38.9 \%$ of the mothers with uterine rupture. $89.9 \%$ of cases of uterine rupture had delay at home which might contribute to this obstetrics tragedy. As indicated in Table 3, the two 
Citation: Bekabil TT (2018) Uterine Rupture among Women who Gave Birth at Nekemte Referral Hospital: Case Control Study. Biol Med (Aligarh) 10: 430. doi:10.4172/0974-8369.1000430

Page 4 of 6

major reasons for delay at home in uterine rupture cases were lack of ambulance service and thinking that home delivery is possible. On the other hand, Table 4 shows $96.3 \%$ of uterine rupture cases were followed for some times either at health centers or private clinics when compared with $51.9 \%$ of mothers gave birth by cesarean section. This might indicate possibility of delay at health facility.

\begin{tabular}{|c|c|c|}
\hline \multicolumn{2}{|c|}{ Variable } & \multirow{2}{*}{$\begin{array}{l}\text { Number (\%) } \\
57(50)\end{array}$} \\
\hline & Complete & \\
\hline & Incomplete & $57(50)$ \\
\hline \multirow{3}{*}{ Type of surgery } & TAH & 29(53.7) \\
\hline & Repair & $21(38.9)$ \\
\hline & STAH & $4(7.4)$ \\
\hline \multirow{4}{*}{ Place of rupture } & Home & 11(20.4) \\
\hline & Health center & $20(37)$ \\
\hline & On the way to health facility & $18(33.3)$ \\
\hline & Hospital & $5(9.3)$ \\
\hline \multirow{4}{*}{ Reason for delay at home and/or health facility } & No delay & $6(11.1)$ \\
\hline & Thinking that she can delivery at home & 21(38.9) \\
\hline & No ambulance service & 21(38.9) \\
\hline & No road for vehicles & $6(11.1)$ \\
\hline
\end{tabular}

Table 3: Levels of delay and characteristics of uterine rupture at Nekemte Referral Hospital from July 2015 to July 2016.

\begin{tabular}{|c|c|c|c|c|c|}
\hline \multirow{2}{*}{\multicolumn{2}{|c|}{ Variables }} & \multicolumn{2}{|c|}{ Study groups } & \multirow[t]{2}{*}{ OR $(95 \% \mathrm{Cl})$} & \multirow[b]{2}{*}{$P$ value } \\
\hline & & $\begin{array}{c}\text { Cases (uterine rupture) } \\
(n=54) n(\%)\end{array}$ & $\begin{array}{l}\text { Control group (cesarean } \\
\text { deliveries) }(n=108) n(\%)\end{array}$ & & \\
\hline \multirow{2}{*}{ Age in years } & $\geq 35$ & $7(13)$ & $7(6.5)$ & \multirow{2}{*}{$2.15(0.71,6.48)$} & \multirow{2}{*}{0.17} \\
\hline & $\leq 34$ & $47(87)$ & 101 (93.5) & & \\
\hline \multirow{2}{*}{ Parity } & $\geq 5$ & $12(22.2)$ & $15(13.9)$ & \multirow{2}{*}{$4.37(1.05,18.23)$} & \multirow{2}{*}{0.04} \\
\hline & $\leq 4$ & $42(77.8)$ & $93(86.1)$ & & \\
\hline \multirow{2}{*}{ ANC } & No & $9(16.7)$ & $3(2.8)$ & \multirow{2}{*}{$7(1.81,27.02)$} & \multirow{2}{*}{0.01} \\
\hline & Yes & $45(83.3)$ & 105 (97.2) & & \\
\hline \multirow{2}{*}{ Educational status } & No formal education & $44(81.5)$ & $70(64.8)$ & \multirow{2}{*}{$2.38(1.08,5.26)$} & \multirow{2}{*}{0.01} \\
\hline & Formal education & $10(19.5)$ & $38(35.2)$ & & \\
\hline \multirow{2}{*}{ Household income } & $\leq 100$ dollars & $52(96.3)$ & $70(64.8)$ & \multirow[t]{2}{*}{$14.08(3.25,62.5)$} & \multirow{2}{*}{0} \\
\hline & $>100$ dollars & $2(3.7)$ & $38(35.2)$ & & \\
\hline \multirow{2}{*}{ Previous cesarean scar } & Yes & $7(13)$ & $23(21.3)$ & \multirow{2}{*}{$0.55(0.22,1.37)$} & \multirow{2}{*}{0.2} \\
\hline & No & $47(87)$ & $85(78.7)$ & & \\
\hline Previous home delivery & Yes & $26(48.1)$ & $10(9.3)$ & $9.10(3.92,21.11)$ & 0 \\
\hline
\end{tabular}




\begin{tabular}{|l|l|l|l|l|l|}
\hline & No & $28(51.9)$ & $98(90.7)$ & \\
\hline \multirow{2}{*}{$\begin{array}{l}\text { Intrapartal follow up at health center or } \\
\text { private clinics }\end{array}$} & Yes & $52(96.3)$ & $56(51.9)$ & $\begin{array}{l}24.14(5.60, \\
104.15)\end{array}$ & 0 \\
\cline { 2 - 6 } & No & $2(3.7)$ & $52(48.1)$ & $1.00(0.287,3.48)$ & 1 \\
\hline \multirow{2}{*}{$\begin{array}{l}\text { Intervention by oxytocin/instrumental } \\
\text { delivery }\end{array}$} & Yes & $4(7.4)$ & $50(92.6)$ & $100(92.6)$ & \\
\cline { 2 - 5 } & No & 50 & \\
\hline
\end{tabular}

Table 4: Associated risk factors for uterine rupture among study participants at Nekemte Referral Hospital from July 2015 to July 2016.

\section{Maternal and neonatal outcome at birth for uterine rupture at Nekemte Referral Hospital}

Uterine rupture caries more maternal $(1.85 \%$ vs. $0 \%)$ and neonatal mortalities ( $96.3 \%$ vs. $3.7 \%$ ) when compared to mothers gave birth by cesarean section. The case fatality rate of uterine rupture in Nekemte Referral hospital was $1.8 \% .48 .1 \%$ of mothers with uterine rupture were transfused with whole blood while only $0.9 \%$ of mothers delivered by cesarean section had blood transfusion. The odds ratio of requiring blood transfusion for uterine rupture was (OR=99, 95\% CI: 12.9, 764) when compared to cesarean deliveries.

\section{Discussion}

Despite advances in modern obstetrics care, intrapartum uterine rupture is continuing catastrophic obstetrics tragedy in resource limited countries where access to medical care is limited because of deep rooted poverty. The incidence of uterine rupture varies among countries based on risk factors operating in a given obstetrics population and standard of obstetric care [8,9]. In this study, its incidence is 1 per 70.5 deliveries. This is high when compared to other studies in developing countries $[8,9]$ which might be explained by limited access to or ineffective obstetric cares, delayed referral, and poor transportation facilities.

Risk factors or etiologies of uterine rupture vary from one part of the world to the other. According to different literatures on this issue, obstructed labor is the leading cause of uterine rupture in resource limited countries whereas previous uterine scar is the major risk factor in developed countries [2]. The major contributing factors for uterine rupture in this study were parity, lack of formal education, lack of antenatal care, low household income, previous home delivery experience before the index pregnancy, and intrapartum follow up at health centers or private clinics. These factors, directly or indirectly, are responsible for the occurrence of obstructed labor.

Many literatures indicated that increasing parity is known to be one of important risk factors for uterine rupture $[5,10]$. Likewise, in this study, the risk of uterine rupture in mothers with parity $\geq 5$ was about 4 times when compared to mothers with parity $\leq 4$. This could be explained by the fact that in women with low parity and especially in primigravidas, when mechanical obstruction occurs, uterine contractions gradually become weaker and stop, while in multi-parous women, the contractions often continue till the uterus ruptures. Therefore, in order to decrease high parity in obstetrics population, the author recommends improved access to family planning services.

Lack of education and low socioeconomic status are important modifiable factors that can affect healthy seeking behavior and access to obstetric cares of pregnant mothers [1]. In this hospital based study, mothers with household income $<100$ USD and with no formal education had about 14 and 2 times respectively the risk of developing uterine rupture when compared to mothers with better income and education. The combined effects of these two factors can bring about poor health seeking behavior, underutilization of antenatal care, family planning and health institution delivery services all of which might directly or indirectly increase the occurrence of uterine rupture in a given society. For instance, in this particular study, pregnant mothers with no antenatal care had about 7 times the risk of uterine rupture when compared to mothers with antenatal care. In addition to this, the risk of uterine rupture was about 9 times in pregnant mothers with history of home delivery before the index pregnancy.

Like many others studies in developing countries [3,5,9,11], the leading cause of uterine rupture was obstructed labor (80\%). $87 \%$ of uterine rupture occurred in unscarred uterus and history of previous uterine scar was only reported in $13 \%$. use of uterotonic agents, instrumental delivers and scared uteri did not show positive association with uterine rupture. Therefore, different sectors should work in a coordinated manner, at community and health facility level, to prevent obstructed labor. Otherwise, uterine rupture in labor will remain with us for a long time.

In modern obstetrics, accessibility to obstetric care alone is not enough to abate complications; particularly, in resource limited setting where there is few number of and/or access to obstetrics facilities, the issue of quality care needs to be emphasized. Amazingly, in this particular study, $96.3 \%$ of uterine rupture cases had intrapartum follow up for some times either at health centers or private clinics when compared to $51.9 \%$ of mothers delivered by cesarean section. This increased the risk of uterine rupture by 24 folds. Majority of uterine rupture had occurred at health facility $(46.3 \%)$ when compared to at home $(20.4 \%)$ and on the way to healthy facility (33.3\%). These findings might indicate possibility of delay at these health facilities, inadequate quality of obstetrics care and/or poor skill and thus needs due attention from the government and nongovernmental stakeholders.

Most of maternal morbidities and mortalities occur because of delays at different levels [12]. In this particular study, majority of cases of uterine rupture $(89.9 \%)$ had some degree of delay at home and/or health facility due to problems related to health seeking behavior of patients or infrastructure like road or ambulance service which might contribute to this obstetrics tragedy.

Ethiopia is one of developing countries where maternal and perinatal mortality rates are still very high. The maternal mortality ratio/MMR in Ethiopia is one of the highest in sub-Saharan African, $412 / 100,000$ live births and the perinatal mortality is also high [13]. One of the major causes of maternal and perinatal mortalities is rupture of the uterus which mainly caused by obstructed labor [5]. In this study, uterine rupture caused higher maternal deaths $(1.85 \%$ vs. 
Page 6 of 6

$0 \%)$ and stillbirths (96.3\% vs. 3.7\%) when compared to mothers delivered by cesarean section for mechanical reasons (Table 5). The maternal death in this study was lower when compared to similar studies in Ethiopia and other developing countries [9] which could be explained by aggressive surgical interventions and availability of blood transfusion. Like other studies in Ethiopia [4,5], fetal outcome is poor.

\begin{tabular}{|l|l|l|l|l|}
\hline \multicolumn{2}{|c|}{} & \multicolumn{3}{c|}{ Study groups } \\
\cline { 3 - 5 } \multicolumn{2}{|c|}{ Variable } & $\begin{array}{c}\text { Cases } \\
\text { (uterine } \\
\text { rupture) } \\
\text { (n=54) n (\%) }\end{array}$ & $\begin{array}{c}\text { Control groups } \\
\text { (cesarean } \\
\text { deliveries) } \\
(\mathbf{n = 1 0 8 )} \mathbf{n}(\%)\end{array}$ & $\begin{array}{c}\text { Total (n=162) } \\
\mathbf{n}(\%)\end{array}$ \\
\hline \multirow{2}{*}{ Maternal outcome } & Alive & $53(98.15)$ & $108(100)$ & $161(99.4)$ \\
\cline { 2 - 5 } & Dead & $1(1.85)$ & $0(0)$ & $1(0.6)$ \\
\hline \multirow{2}{*}{$\begin{array}{l}\text { Neonatal } \\
\text { outcome }\end{array}$} & Alive & $2(3.7)$ & $104(96.3)$ & $106(65.4)$ \\
\cline { 2 - 5 } & Dead & $52(96.3)$ & $4(3.7)$ & $56(34.6)$ \\
\hline
\end{tabular}

Table 5: Maternal and neonatal outcome at delivery of uterine rupture at Nekemte Referral Hospital from July 2015 to July 2016.

Though the standard management of ruptured uterus is hysterectomy, repair can be considered based on parity, duration of rupture, site of rupture, experience of practitioner, health seeking behavior and general condition of the patient $[3,5]$. In this study, most of the patients were managed with hysterectomy (61.1\%).

\section{Conclusion and Recommendation}

Magnitude of uterine rupture was high in the study area. It carries more maternal and perinatal complications. There were numerous modifiable predisposing factors and delays at patient, infrastructure and facility level. Therefore, the author recommends the responsible governmental and non-governmental stakeholders to act at various levels in organized and comprehensive approach in order to abate this clinical and public health problem.

\section{Acknowledgements}

I would like to acknowledge Wollega University, College of Medical and Health Sciences, school of medicine for giving this opportunity to conduct this paper. Last but not least, my special thanks go to midwifery staffs of obstetrics and gynecology ward in Nekemte Referral Hospital particularly Mr. Birhanu Nemomsa (BSc in midwifery) and medical interns specially Dr. Demelash Gonfa for their active participation in data collection and patient follow up.

\section{Authors' Contributions}

TT was involved in all processes of this research work, including conception, design, supervision of data collection, data analysis and write up of the manuscript. All authors read and approved the final manuscript.

\section{Competing Interests}

The author declares that he has no competing interests.

\section{References}

1. Mukasa Pk, Kabakyenga J, Senkungu JK, Ngonzi J, Kyalimpa M, et al. (2013) Uterine rupture in a teaching hospital in Mbarara,western Uganda, unmatched case- control study. Reprod Health 10: 29.

2. Hofmeyr GJ, Say L, Gulmezoglu AM (2005) WHO systematic review of maternal mortality and morbidity: the prevalence of uterine rupture. Obstet Gynecol Int J 112: 1221-1228.

3. Latika S (2006) A 10-year analysis of uterine rupture at a teaching institution. J Obstet Gynecol India 56: 502-506.

4. Admassu A (2004) Analysis of ruptured uterus in Debre Markos hospital, Ethiopia. East Afr Med J 81: 52-55.

5. Gassessew A, Melese M (2002) Ruptured uterus - eight-year retrospective analysis of causes and management outcome in Adigrat Hospital, Tigray region, Ethiopia. Ethiopia J Health Dev 16: 241-245.

6. Padhye SM (2005) Rupture of the pregnant uterus - A 20-year review. Kathmandu University Medical Journal 3: 234-238.

7. Rizwan N, Abbasi RM, Uddin SF (2011) Uterine rupture, frequency of cases and fetomaternal outcome. JPMA 61: 322.

8. Yilmaz M (2011) The evaluation of uterine rupture in 61 Turkish pregnant women. Eur J Gen Med 8: 194-199.

9. Ehigiegbaa AE, Adeyemo IS (2006) Uterine rupture in labour: A continuing obstetric challenge in developing countries- The Benin experience. Journal of Medicine and Biomedical Research 5: 44-50

10. Konje JC, Odukoya OA, Ladipo OA (1990) Rupture uterus in Ibadan. A twelve-year review. Int J Gynaecol Obstet 32: 207-213.

11. Dhaifalah I, Santavy J, Fingerova H (2006) Uterine rupture during pregnancy and delivery among women attending the Al-Tthawra hospital in Sana'a city Yemen republic. Biomed Pap Med Fac Univ Palacky Olomouc Czech Repub 150: 279-283.

12. Bennouna C, Feldman B, Usman R, Adiputra R, Kusumaningrum S, et al. (2016) Using the three delays model to examine civil registration barriers in Indonesia. PLoS ONE 11: e0168405.

13. Federal Democratic Republic of Ethiopia (2016) Demographic and health survey. Key indicators report. Addis Ababa, Ethiopia. 